\title{
Development of Textile Proximity Sensor for Medication Adherence Management System
}

\author{
Jong Gab Ho ${ }^{1}$ and Se Dong Min ${ }^{1 *}$ \\ ${ }^{1}$ Department of Medical Information Technology Engineering, Soonchunhyang University, \\ Asan, South Korea \\ [e-mail: hogabi1988@gmail.com, sedongmin@sch.ac.kr] \\ *Corresponding author: Se Dong Min
}

Received September 30, 2017; accepted December 28, 2017; published February 28, 2018

\begin{abstract}
In this study, we developed textile proximity sensor using conductive textile to develop a Medication adherence management system. The textile proximity sensor utilizes the principle of the capacitor, and the ring type sensor used to reduce the fringe-effect. When take medicines, we made a custom PCB that converts the change of the data measured by the sensor into a digital value so that transmitted the PC. In order to compare the performance of the system, we evaluated the correlation between the data variation according to the quantity of pills in the electronic compact scale and the data in this system. As a result, Pearson's correlation coefficient was $0.956(\mathrm{p}<0.01)$, confirmed a good correlation between the scale and our system. Therefore, we concluded that our system evaluated able to whether or not to take medication.
\end{abstract}

Keywords: Conductive textile, Proximity sensor, Pill case, Medication adherence, Medication management

A preliminary version of this paper was presented at APIC-IST 2017, and was selected as an outstanding paper. This research was supported by the Soonchunhyang University Research Fund and the Bio \& Medical Technology Development Program of the National Research Foundation (NRF) funded by the Ministry of Science, ICT \& Future Planning (NRF-2015M3A9D7067388). 


\section{Introduction}

Medication adherence is generally indicated by the doctor and pharmacists taking the prescribed amount of medicine and number of times [1]. Adherence to medication compliance is a important act in effectively treating illness and restoring health [2]. However, it does not follow medication adherence as much as doctors and pharmacists expect. This causes problems in the reliability of the doctor and the pharmacist, but more importantly, it can lead to problems in the patient's health. In a study conducted in the United States(US) to determine the importance of medication adherence in terms of the risk of death and the cost of medical care for patients enrolled in the US Medcaid program. As a result, the risk of death among patients with medication adherence below $80 \% 3$ times higher. Also, hospital visits were $86 \%$, and emergency transport visits increased by 50\% [3].

In order to solve medication non-adherence, various researches have been conducted on the system that helps the medication adherence. Studies have been conducted to evaluate whether a wearable device is manufactured and adhered to the medication, and it includes a research that uses an inertial sensor to wear on the wrist to detect adherence with medication [4-5]. Also, a study to predict medication adherence using a piezoelectric sensor and a vibration sensor [6]. And a study conducted to measure adherence with an ingestible sensor [7]. In addition, medication adherence studies were conducted include smart pill box using a 3-axis accelerometer sensor [8-9], and using load cell [10].

On the other hand, wearable technology based on conductive textiles has attracted attention in various fields such as medical [11], commercial, military, and aerospace industries. This is because it is technically possible to make the part where the limitations exist only with the exisitng electronic devices. In addition, since conductive textiles are human-friendly materials. There is an advantage that the conductive textiles can be used without discomfort by users. In recent research, a study on healthcare using conductive textile has been conducted [12-17].

Especially, studies on human cyclical behavior and biological activities are underway. As a periodic action, researches are conducted on sitting postures study [18-20] and walking study [21-22] using textile sensors. Research on biometrics [23-29] is also being conducted. With the development of conductive textiles and the use of fibers, human life weill be further imporoved in the future.

In this study, a textile sensor was fabricated by using conductive textile to implement a Medication adherence management system. Previous studies have been many sensors, large, heavy, and mostly mechanical system studies. We propose a system that conductive textiles, which are small, light and human-friendly material, to solve the above problems.

The paper is structured as follows : Section 2 presents the principle and implementation of the conductive textile proximity sensor. Section 3 describes the proposed system. After Section 4 and 5, we describes the experiment and result, discussion respectively. Section 6 summarized about our study. 


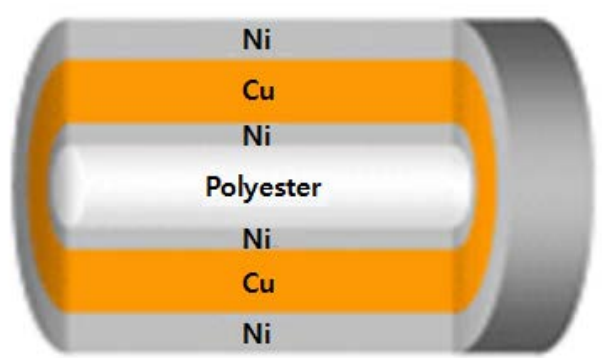

Fig. 1. Structure of Conductive textile

\section{Conductive Textile Proximity Sensor}

\subsection{Conductive Textile}

Conductive textiles are coating a conductive material such as nickel $(\mathrm{Ni})$ or cooper $(\mathrm{Cu})$ on the textiles to allow electricity to pass through the textiles. The structure of the conductive textile is shown in Fig. 1. It is have the advantage of having conductive and shielding effect, easy to fabricate the sensor, and can be manufactured in various forms.

In this study, we designed a system for evaluating medication adherence by fabricating a textile proximity sensor using conductive textiles. The conductive textile model was W-290-PCN (Ajin electron, Busan, South Korea) and the properties of the conductive textiles are shown in Table 1.

Table 1. Characterizes of Conductive textile

\begin{tabular}{|c|c|}
\hline Item & W-290-PCN \\
\hline \hline Textile type & Woven \\
\hline Base material & Polyester \\
\hline Width $(\mathrm{mm})$ & $1100 \pm 5$ \\
\hline Weight $\left(\mathrm{g} / \mathrm{m}^{2}\right)$ & $81 \pm 5$ \\
\hline Thickness $(\mathrm{mm})$ & $0.1 \pm 0.01$ \\
\hline Density $\left(\mathrm{g} / \mathrm{cm}^{3}\right)$ & $188 \pm 5$ \\
\hline
\end{tabular}

\subsection{Textile Proximity Sensor}

The textile proximity sensor derives the capacitance value based on capacitor theory. Fig. 2 . Shows a parallel plate capacitor method that is basic capacitor. The Formula for obtaining the capacitor value in parallel plate capacitors is the equation (1).

$$
\mathrm{C}=\frac{\varepsilon_{\mathrm{r}} \times \epsilon_{0} \times \mathrm{A}}{\mathrm{d}}
$$

$\varepsilon_{\mathrm{r}}$ is the delectric constant of the material placed between the two plates, and $\varepsilon_{0}$ is the permittivity of free space $\left(8.85 \times 10^{-12} F / m\right)$. A is the Area of the plate (width $\times$ length), and 
$\mathrm{d}$ is the distance between the two plates(in meters). However, in the sensor implementation, the value of $\varepsilon_{\mathrm{r}}$, $\varepsilon_{0}$, A does not change, so the capacitance value is determined by $\mathrm{d}$.

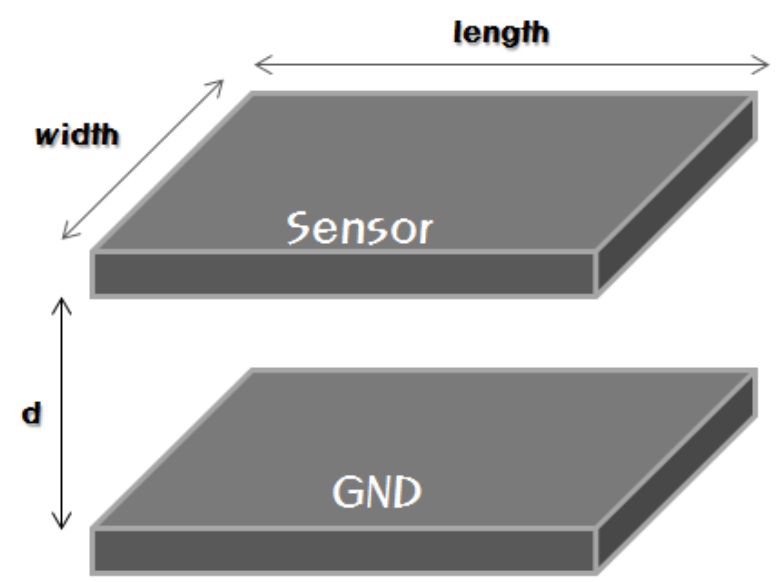

Fig. 2. Parallel Plate Capacitor

For a basic capacitor of two parallel plates in Fig. 2, a fringe effect occurs. The fringe effect has a problem affecting the measurement accuracy of the system and occurs near the edge of the plate. Therefore, in this study, a ring-type capacitor sensor was fabricated to minimize the effect of the fringe effect [30].

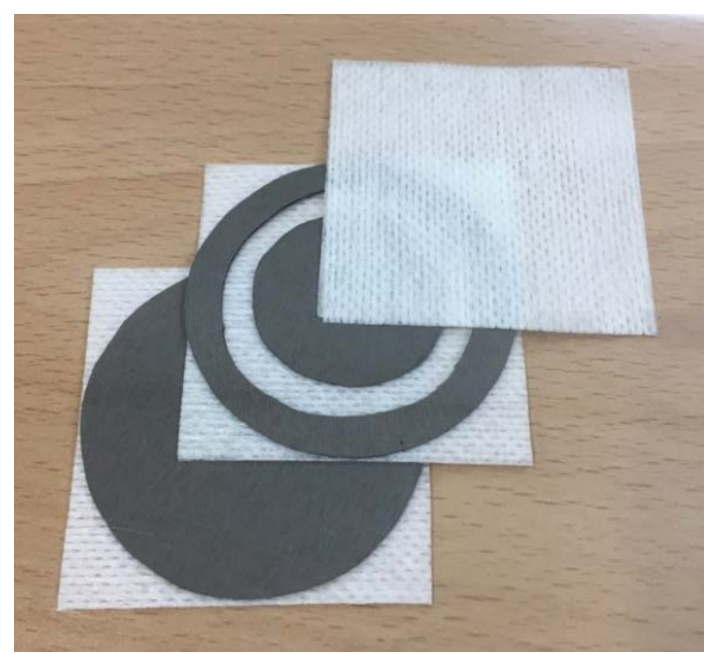

Fig. 3. Ring-type Textile Proximity Sensor

The fabricated sensor consists of a sensor part, a shield part, and a material. A $5 \times 5 \mathrm{~cm}^{2}$ square medical textile bandage was used for the material. The sensor part is $3 \times 3 \mathrm{~cm}^{2}$ circular size to fit the size of the pill case, and the shield part is made of $5 \times 5 \mathrm{~cm}^{2}$ circular size and ring type of width $0.5 \mathrm{~cm}$ as shown Fig. 3 . 


\section{Medication Adherence Management System}

We designed overall system based on the textile proximity sensor designed for medication adherence. Fig. 4 shows the Medication adherence management system.

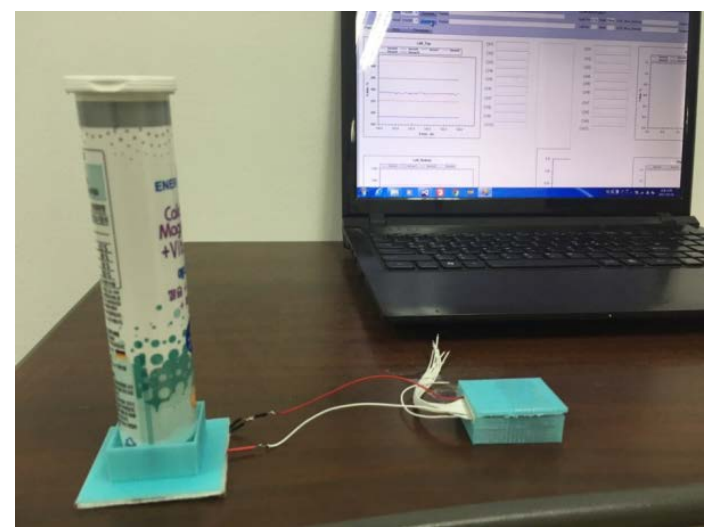

Fig. 4. Medication Adherence Management System

In order to transmit the capacitance value generated by the textile sensor to Personal Computer(PC), custom Printed Circuit Board (cusotm PCB) was fabricated using MPR 121 chip based on Synchronous Transfer Mode (STM) and BC417 chip providing Bluetooth (BTH) communication. The custom PCB is shown in Fig. 5, and the battery able operate for up to 8hours.

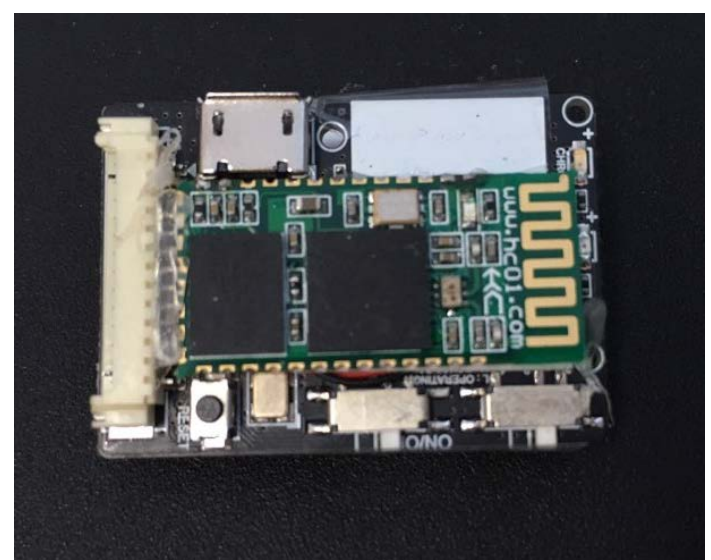

Fig. 5. Design of custom Printed Circuit Board

In previous study [31], there is a problem that unstable data appeared due to a position where a pill case was placed in a textile sensor, and noise due to the PCB and the battery occured. To solve the problem, Sensor barrier and PCB guard were designed using Replicator 2 (MakerBot, New York City, United States), a 3D printer model. Sensor barrier and PCB guard design are Shown in Fig. 6. The sensor barrier was designed with $5 \mathrm{~cm}$ width, $5 \mathrm{~cm}$ length and $0.2 \mathrm{~cm}$ height according to the sensor size. The wall part of the sensor barrier was designed with $3 \mathrm{~cm}$ width, $3 \mathrm{~cm}$ length, $1.3 \mathrm{~cm}$ height accrding to the size of pill case. And the PCB guard is designed to be $4 \mathrm{~cm}$ width, $3 \mathrm{~cm}$ length, $1.3 \mathrm{~cm}$ height according to the size of PCB. And it is possible to power line and sensor connection line were connected through hole of $1.5 \mathrm{~cm} \times 0.8 \mathrm{~cm}$ and $2 \mathrm{~cm} \times 0.5 \mathrm{~cm}$, respectively. 


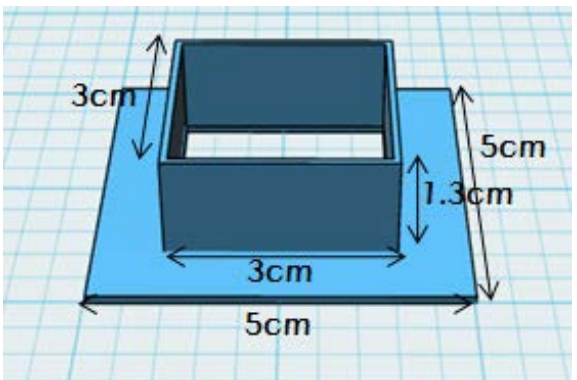

(a) sensor barrier

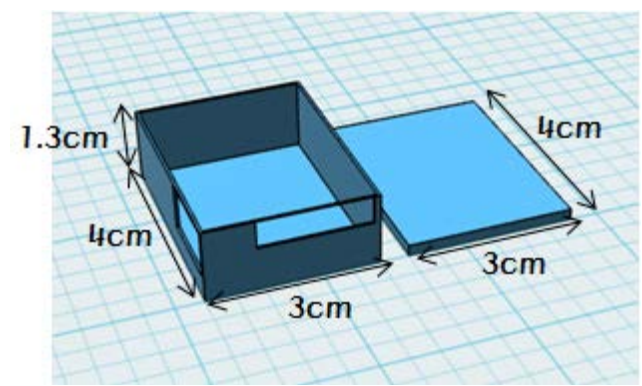

(b) PCB guard

Fig. 6. 3D printing design

\section{Experiments}

\subsection{Textile Proximity Sensor Evaluation}

In the previous study, we measured the capacitance of the LCR meter using LCR-8110G (GW Instek, New Taipei City, Taiwan) to confirm the resolution of the textile sensor [31]. In addition, was measured using an electronic compact scale model SF-400C (Suofei electronic, Jiangsu, China) to confirm the weight data according to the quantity of pills. The properties of the electronic compact scale are shown in Table 2. The pill used was 15T (Tablet, 6,000mg×15) multi-vitamin EnerHeim (Nutrilo GmbH, Cuxhaven, Germany). As a result, a graph was shown linearly, as shown in Fig. 7, and the average weight of the pill was $6.036 g( \pm 0.064)$. Based on the pill data measured using the electronic compact scale, we acquired the data according to quantity of pills with the textile proximity sensor that we implemented and correlated between the two data to evaluate whether our sensor correlated with the criteria for the electronic compact scale.

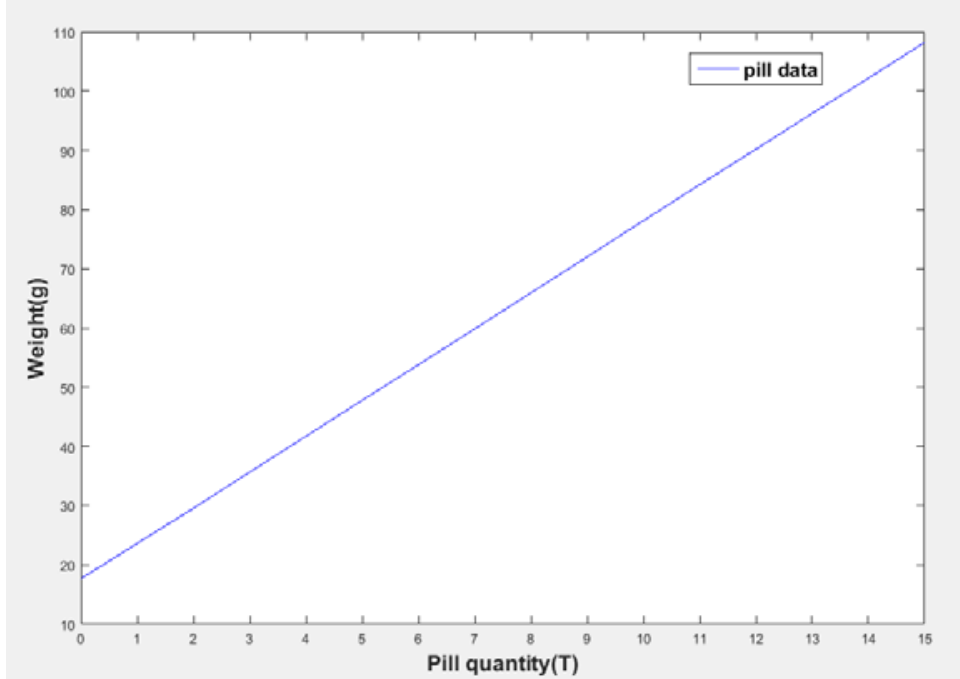

Fig. 7. weight for each pill quantity using electronic compact scale 
Table 2. Characterizes of Electronic compact scale

\begin{tabular}{|c|c|}
\hline Item & SF-400C \\
\hline \hline Measurement Unit & $0.01 \mathrm{~g}$ \\
\hline Maximum Measurement & $500 \mathrm{~g}$ \\
\hline Product Size $\left(\mathrm{mm}^{3}\right)$ & 225 x 115 x 43 \\
\hline
\end{tabular}

\subsection{Take Medication Scenario}

In order to evaluate medication adherence, we designed a scenario in which medication patients take pills. At first, the patient measures on the data of sensor before taking the medication. Next, patient takes the medication to take the pill case, and place the pill case on the textile sensor. Finally, measures data of sensor after taking the medication. Take medication scenario step is shown in Table 3.

Table 3. Medication Scenario

\begin{tabular}{|c|c|}
\hline Step & Action \\
\hline \hline a & Measures pre-medication data \\
\hline b & Take the pill case from the sensor \\
\hline c & Take medication \\
\hline d & Place the pill case on the textile sensor \\
\hline e & Measures post-medication data \\
\hline
\end{tabular}

\subsection{Data Communication}

Capacitance value was converted into digital value and transmitted to PC to show the capacitance value, which is the data that is generated when the pill case placed on the sensor. To convert a digital value, a custom PCB transfers data through $\mathrm{I}^{2} \mathrm{C}$ communication and converts the data through an ADC. Then, transmitted data to the PC Through BTH communication. In order to check the transmitted capacitance value, the data of textile proximity sensor can be confirmed and stored in real-time through implement of application using C\# language in Visual Studio 2017 as shown in Fig. 8.

\subsection{Data Acquisition}

Based on the constructed system, we acquired data the change of capacitance value every time we take medication. We set the sampling rate of the data to $100 \mathrm{~Hz}$, check the data in real-time through C\# application, and collect the data through the storage function. The experiment was conducted in total of 7 times experiments according to the take medication scenario from 15T when the pill was full in pill case to 0T when the pill was empty. 


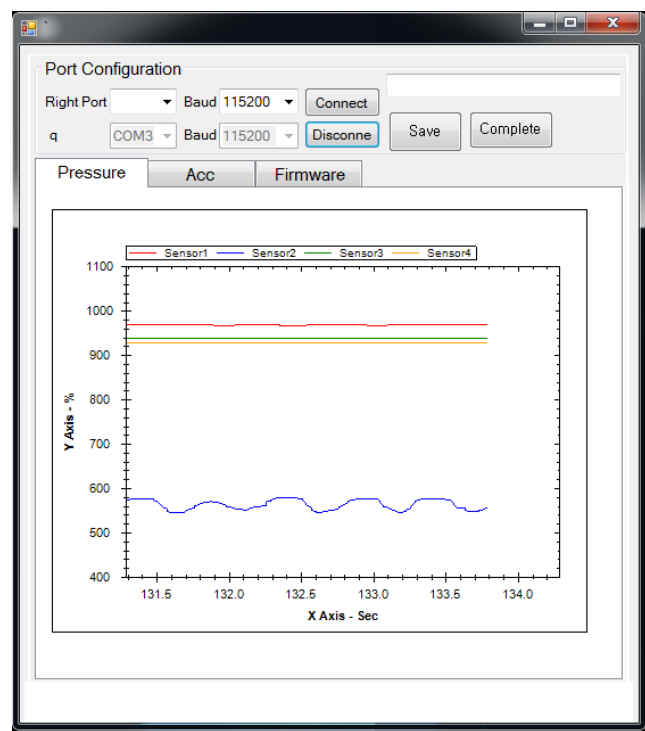

Fig. 8. Application based on C\# language.

\subsection{Signal Processing}

The graph of the raw data acquired through the experiment is shown in Fig. 9. Fig. 9(a) is a state in which the pill is full in pill case, that is, 15T. Fig. 9(b) is a state in which the pill is vacant in pill case by repeating the take medication scenario(Table 3). Fig. 9(c) shows a series of procedures for take medication that taking pill case and place it down.

We apply the Moving Average Filter (MAF, $N=15$ ) to reduce the noise and staircase phenomena because the data can affect the result by the influence of the staircase phenomenon and noise in the acquired data. And Fig. 9(c) was detected using the peak detection algorithm. After peak detection, the time required to stabilize the data was 1 second, and the data values for 1.5 seconds after stabilization were extracted as Region of Interst (ROI). The average value was acquired from the extracted ROI data and used as the evaluation index of the medication adherence.

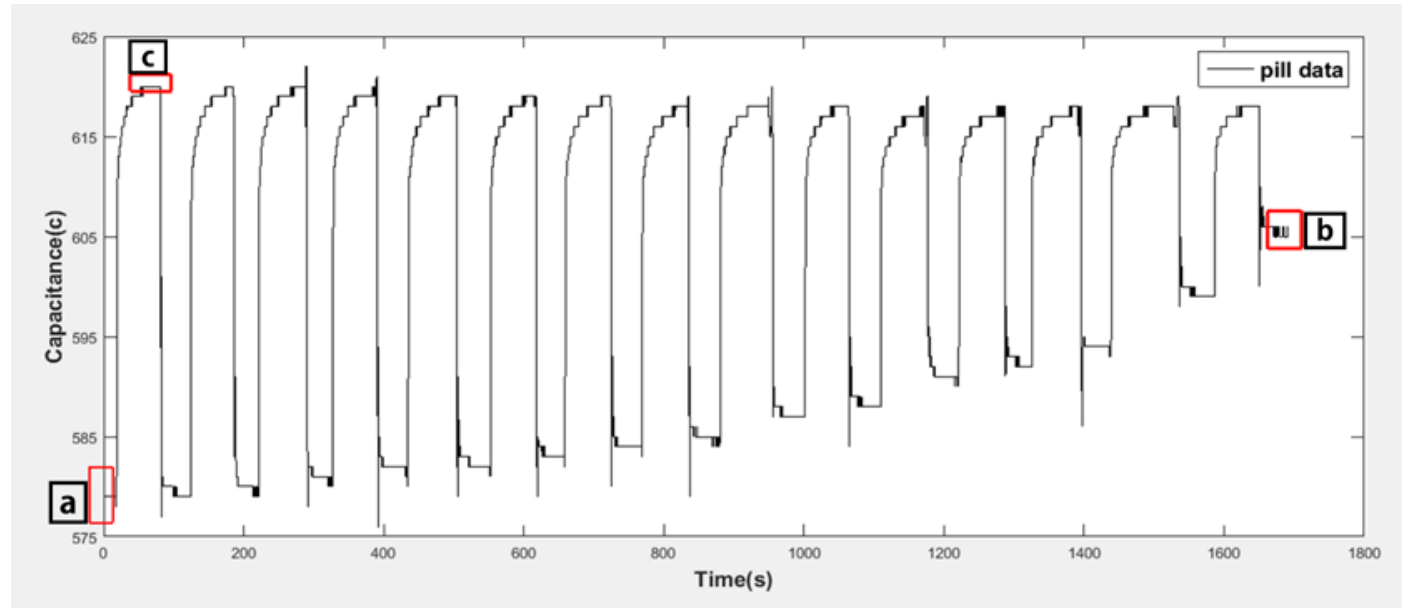

Fig. 9. Raw data for pill quantity when take medication 


\subsection{Statistical Analysis}

In order to confirm the correlation between the pill data of electronic compact scale and the textile proximity sensor based on conductive textile. We used Pearson's correlation between two groups of data using SPSS Statistics version 18.0 (IBM, New York City, United States) to evaluate the correlation between the two group's data.

\section{Results and Discussion}

We conducted an experiment to evaluate whether there is a change in data at the time of medication adherence according to the medication scenario.

Table 4. Result data of each experiment

\begin{tabular}{|c|c|c|c|c|c|c|c|c|}
\hline \hline & \multicolumn{9}{|c|}{ Experiments } & \\
\hline \hline Pill quantity & $\mathbf{1}$ & $\mathbf{2}$ & $\mathbf{3}$ & $\mathbf{4}$ & $\mathbf{5}$ & $\mathbf{6}$ & $\mathbf{7}$ & Ave. \\
\hline $15 \mathrm{~T}$ & 605.74 & 593.07 & 594.00 & 586.94 & 588.06 & 584.00 & 585.00 & 590.97 \\
\hline $14 \mathrm{~T}$ & 599.49 & 588.00 & 589.74 & 581.94 & 584.00 & 579.88 & 581.00 & 586.29 \\
\hline $13 \mathrm{~T}$ & 594.00 & 585.80 & 586.00 & 581.00 & 582.00 & 577.00 & 578.97 & 583.53 \\
\hline $12 \mathrm{~T}$ & 592.58 & 583.96 & 585.00 & 579.00 & 580.00 & 576.00 & 577.00 & 581.93 \\
\hline 11 & 591.00 & 582.02 & 582.76 & 578.00 & 579.00 & 575.00 & 576.00 & 580.54 \\
\hline 10 & 588.00 & 580.00 & 581.00 & 576.00 & 577.00 & 574.00 & 575.00 & 578.71 \\
\hline $9 \mathrm{~T}$ & 587.00 & 579.00 & 580.00 & 575.00 & 576.00 & 572.82 & 573.20 & 577.57 \\
\hline $8 \mathrm{~T}$ & 585.00 & 578.12 & 579.00 & 574.93 & 575.98 & 571.00 & 572.42 & 576.63 \\
\hline $7 \mathrm{~T}$ & 584.00 & 577.96 & 578.00 & 574.00 & 573.00 & 570.00 & 571.65 & 575.51 \\
\hline $6 \mathrm{t}$ & 583.00 & 576.01 & 576.99 & 572.98 & 573.15 & 569.01 & 571.00 & 574.59 \\
\hline $5 \mathrm{~T}$ & 582.58 & 575.97 & 575.00 & 572.00 & 573.02 & 569.00 & 571.00 & 574.08 \\
\hline $4 \mathrm{~T}$ & 582.00 & 575.00 & 575.06 & 571.00 & 571.89 & 568.00 & 569.00 & 573.13 \\
\hline $3 \mathrm{~T}$ & 581.01 & 574.00 & 574.00 & 571.00 & 571.48 & 567.01 & 568.93 & 572.49 \\
\hline $2 \mathrm{t}$ & 580.00 & 573.00 & 574.00 & 571.00 & 571.00 & 567.00 & 568.50 & 572.07 \\
\hline $1 \mathrm{~T}$ & 579.63 & 573.00 & 574.00 & 569.00 & 570.00 & 566.19 & 568.00 & 571.40 \\
\hline $0 \mathrm{~T}$ & 579.00 & 571.76 & 573.00 & 567.99 & 569.00 & 566.00 & 566.50 & 570.46 \\
\hline
\end{tabular}

Unit: Capacitance value $(\mathrm{pF})$

T: Tablet, Ave.: Average

The experiment has seven times in total, and a result of experiment as shown in Table 4. The data value for each experiment in Table 4 represenst the capacitance value(pF), and the capacitance value decreases gradually as the quantity of pill decreases. However, although quantity of pills in Table 4 is reduced, the section where the data value is same or the section where the data is increased have been confirmed. In this problem, we considered that the data of the $\mathrm{y}$-axis in the program code of the C\# application is set to be too insensitive. This problem will be resolved by checking and correcting the problems of the code. 


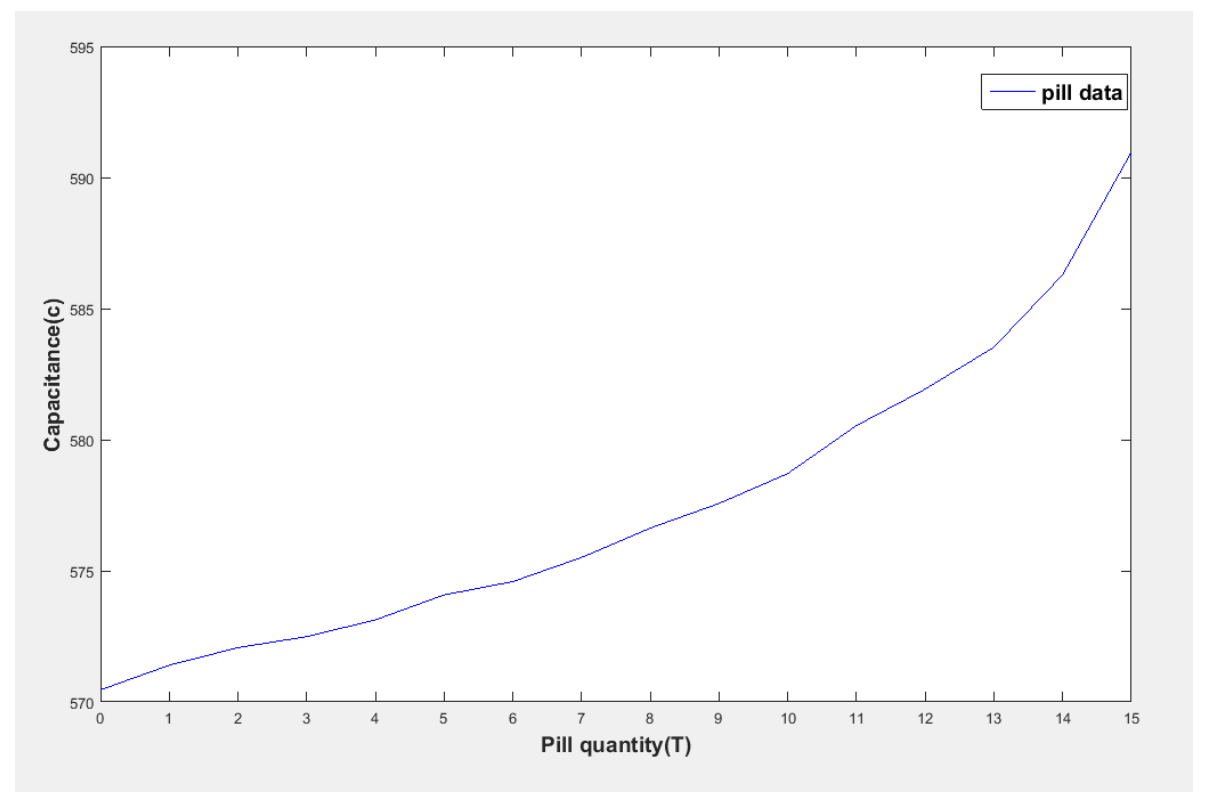

Fig. 10. Pill average data for pill quantity

The data measured with proposed system in Table 4. each experiment data value were averaged to evaluate the overall system stability. The average value of the capacitance value by each quantity of pill was derived. The change of the data is expressed by a graph as shown Fig. 10.

Table 5. Pearson's correlation coefficient of experiment data and electronic scale data

\begin{tabular}{|c|c|}
\hline \hline Experiments & Pearson' r \\
\hline \hline 1 & $0.932^{* *}$ \\
\hline 2 & $0.956^{* *}$ \\
\hline 3 & $0.950^{* *}$ \\
\hline 4 & $0.963^{* *}$ \\
\hline 5 & $0.960^{* *}$ \\
\hline 6 & $0.960^{* *}$ \\
\hline 7 & $0.962^{* *}$ \\
\hline Ave. & $0.956^{* *}$ \\
\hline Ave.: Average & $\mathrm{p}<0.01$ \\
\hline
\end{tabular}

Fig. 10 shows that the capacitance value gradually increases with the increase of the pill. Then, we evaluated the correlation between proposed system and electronic compact scale through Pearson's correlation. The Pearson's correlation result of experiment data and electronic scale data as shown in Table 5.

The results showed that the lowest correlation coefficient was 0.932 and the highest correlation coefficient was 0.963 for each of the seven experiments. Moreover, for the average data, a correlation coefficient of 0.956 , and the results were statistically significant for all experiments [32]. As a result, we concluded that our system able evaluate drug compliance when taking medication. 


\section{Conclusion}

In this study, a textile proximity sensor using conductive textile fabricated to propose a Medication adherence management system. The findings of the studies suggest that we concluded that it is possible to evaluate in our system for the quantity of pills that decrease every time they take medication. However, we have found that small problem that needs to be more sensitive to the resolution of the system. Further study is after solving the resolution problem of the system, we will add a service function that will help the medication adherence patient to maintain adherence with the medication in cooperation with the smart device in android application. In addition, we are trying to experiment our system using in real-life. Finally, we expect that proposed system using textile proximity sensor to be utilized various studies.

\section{References}

[1] Osterberg, Lars, and Terrence Blaschke, "Adherence to medication," New England Journal of Medicine, vol. 353, no. 5, 487-497, 2005. Article (CrossRef Link)

[2] Cramer, J. A., Roy, A., Burrell, A., Fairchild, C. J., Fuldeore, M. J., Ollendorf, D. A., \& Wong, P. $\mathrm{K}$, "Medication compliance and persistence: terminology and definitions," Value in health, vol. 11, no. 1, 44-47, 2008. Article (CrossRef Link)

[3] Faught, E., Duh, M. S., Weiner, J. R., Guerin, A., \& Cunnington, M. C, "Nonadherence to antiepileptic drugs and increased mortality Findings from the RANSOM Study," Neurology, vol. 71, no. 20, 1572-1578, 2008. Article (CrossRef Link)

[4] Chen, C., Kehtarnavaz, N., \& Jafari, R, "A medication adherence monitoring system for pill bottles based on a wearable inertial sensor," in Proc. of Engineering in Medicine and Biology Society (EMBC), 2014 36th Annual International Conference of the IEEE, pp. 4983-4986, IEEE, 2014, August. Article (CrossRefLink)

[5] Kalantarian, H., Alshurafa, N., \& Sarrafzadeh, M, "Detection of gestures associated with medication adherence using smartwatch-based inertial sensors," IEEE Sensors Journal, vol. 16, no. 4, 1054-1061, 2016. Article (CrossRefLink)

[6] Kalantarian, H., Motamed, B., Alshurafa, N., \& Sarrafzadeh, M, "A wearable sensor system for medication adherence prediction,” Artificial intelligence in medicine, vol. 69, 43-52, 2016. Article (CrossRefLink)

[7] Hafezi, Hooman, et al, "An ingestible sensor for measuring medication adherence," IEEE Transactions on Biomedical Engineering, vol. 62, no. 1, 99-109, 2015. Article (CrossRefLink)

[8] Li, J., Peplinski, S. J., Nia, S. M., \& Farajidavar, A, "An interoperable pillbox system for smart medication adherence," in Proc. of Engineering in Medicine and Biology Society (EMBC), 2014 36th Annual International Conference of the IEEE, pp. 1386-1389, IEEE, 2014, August.

Article (CrossRefLink)

[9] Lee, M. L., \& Dey, A. K., "Real-time feedback for improving medication taking," in Proc. of Proceedings of the 32nd annual ACM conference on Human factors in computing systems, pp. 2259-2268. ACM, April 2014. Article (CrossRefLink)

[10] Kim, B. J., "Developing a smart pillbox to improve the medication adherence of the patients requiring a long-term administration," The Journal of the Korea institute of electronic communication sciences, vol. 8, no. 4, 611-617, 2013. Article (CrossRefLink)

[11] Chang, W. W., Sung, T. J., Huang, H. W., Hsu, W. C., Kuo, C. W., Chang, J. J., ... \& Yang, Y. J., "A smart medication system using wireless sensor network technologies," Sensors and Actuators A: Physical, vol. 172, no. 1, 315-321, 2011. Article (CrossRefLink)

[12] Axisa, F., Schmitt, P. M., Gehin, C., Delhomme, G., McAdams, E., \& Dittmar, A., "Flexible technologies and smart clothing for citizen medicine, home healthcare, and disease prevention," IEEE Transactions on information technology in biomedicine, vol. 9, no. 3, 325-336, 2005. Article (CrossRefLink) 
[13] Coyle, S., Lau, K. T., Moyna, N., O'Gorman, D., Diamond, D., Di Francesco, F., ... \& Taccini, N., “BIOTEX-Biosensing textiles for personalised healthcare management," IEEE Transactions on Information Technology in Biomedicine, vol. 14, no. 2, 364-370, 2010. Article (CrossRefLink)

[14] Grillet, A., Kinet, D., Witt, J., Schukar, M., Krebber, K., Pirotte, F., \& Depre, A., “Optical fiber sensors embedded into medical textiles for healthcare monitoring,” IEEE Sensors Journal, vol. 8, no. 7, 1215-1222, 2008. Article (CrossRefLink)

[15] López, G., Custodio, V., \& Moreno, J. I., "LOBIN: E-textile and wireless-sensor-network-based platform for healthcare monitoring in future hospital environments," IEEE Transactions on Information Technology in Biomedicine, vol. 14, no. 6, 1446-1458, 2010. Article (CrossRefLink)

[16] Paradiso, R., Loriga, G., Taccini, N., Gemignani, A., \& Ghelarducci, B., "WEALTHY-a wearable healthcare system: new frontier on e-textile," Journal of Telecommunications and Information Technology, 105-113, 2005. Article (CrossRefLink)

[17] Pacelli, M., Loriga, G., Taccini, N., \& Paradiso, R., "Sensing fabrics for monitoring physiological and biomechanical variables: E-textile solutions," in Proc. of Medical Devices and Biosensors, 2006. 3rd IEEE/EMBS International Summer School on, pp. 1-4. IEEE, 2006, September.

Article (CrossRefLink)

[18] George, B., Zangl, H., Bretterklieber, T., \& Brasseur, G., “A combined inductive-capacitive proximity sensor for seat occupancy detection,” IEEE transactions on instrumentation and measurement, vol. 59, no. 5, 1463-1470, 2010. Article (CrossRefLink)

[19] Meyer, J., Arnrich, B., Schumm, J., \& Troster, G., "Design and modeling of a textile pressure sensor for sitting posture classification,” IEEE Sensors Journal, vol. 10, no. 8, 1391-1398, 2010. Article (CrossRefLink)

[20] Xu, W., Huang, M. C., Amini, N., He, L., \& Sarrafzadeh, M. (2013). “ecushion: A textile pressure sensor array design and calibration for sitting posture analysis,” IEEE Sensors Journal, vol. 13, no. 10, 3926-3934. Article (CrossRefLink)

[21] Mengüç, Y., Park, Y. L., Pei, H., Vogt, D., Aubin, P. M., Winchell, E., ... \& Walsh, C. J., "Wearable soft sensing suit for human gait measurement," The International Journal of Robotics Research, vol. 33, no. 14, 1748-1764, 2014. Article (CrossRefLink)

[22] Tirosh, O., Begg, R., Passmore, E., \& Knopp-Steinberg, N., "Wearable textile sensor sock for gait analysis,” in Proc. of Sensing Technology (ICST), 2013 Seventh International Conference on, pp. 618-622. IEEE, 2013, December. Article (CrossRefLink)

[23] Mattmann, C., Amft, O., Harms, H., Troster, G., \& Clemens, F., "Recognizing upper body postures using textile strain sensors," in Proc. of Wearable Computers, 2007 11th IEEE International Symposium on, pp. 29-36. IEEE, 2007, October. Article (CrossRefLink)

[24] Enokibori, Y., \& Mase, K, "Human joint angle estimation with an e-textile sensor," in Proc. of Proceedings of the 2014 ACM International Symposium on Wearable Computers, pp. 129-130, 2014, September. ACM. Article (CrossRefLink)

[25] Meyer, J., Lukowicz, P., \& Troster, G, “Textile pressure sensor for muscle activity and motion detection," in Proc. of Wearable Computers, 2006 10th IEEE International Symposium on, pp. 69-72, 2006, October. IEEE. Article (CrossRefLink)

[26] Holleczek, T., Rüegg, A., Harms, H., \& Tröster, G, “Textile pressure sensors for sports applications,” in Proc. of Sensors, 2010 IEEE, pp. 732-737, 2010, November. IEEE. Article (CrossRefLink)

[27] Kim, S., Leonhardt, S., Zimmermann, N., Kranen, P., Kensche, D., Muller, E., \& Quix, C, "Influence of contact pressure and moisture on the signal quality of a newly developed textile ECG sensor shirt," in Proc. of Medical Devices and Biosensors, 2008. ISSS-MDBS 2008. 5th International Summer School and Symposium on, pp. 256-259, IEEE, June 2008. Article (CrossRefLink)

[28] Catrysse, M., Puers, R., Hertleer, C., Van Langenhove, L., Van Egmond, H., \& Matthys, "DTowards the integration of textile sensors in a wireless monitoring suit," Sensors and Actuators A: Physical, vol. 114, no. 2, 302-311, 2004. Article (CrossRefLink) 
[29] Huang, C. T., Tang, C. F., \& Shen, C. L., “A wearable textile for monitoring respiration, using a yarn-based sensor," in Proc. of Wearable Computers, 2006 10th IEEE International Symposium on, 2006, October. IEEE. Article (CrossRefLink)

[30] Eren, H., \& Sandor, L. D., "Fringe-effect capacitive proximity sensors for tamper proof enclosures," in Proc. of Sensors for Industry Conference, pp. 22-26, 2005, February. IEEE. Article (CrossRefLink)

[31] Ho, J. G., Wang, C., \& Min, S. D, "A Study of Medication Adherence Using Textile Proximity Sensor," The Transactions of The Korean Institute of Electrical Engineers, vol. 65, no. 7, 1257-1262, 2016. Article (CrossRefLink)

[32] Lawrence, I., \& Lin, K, "A concordance correlation coefficient to evaluate reproducibility," Biometrics, 255-268, 1989. Article (CrossRefLink)

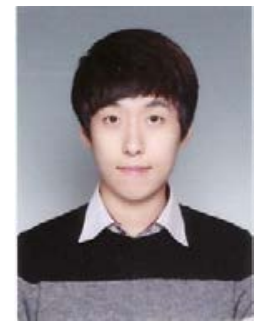

Jong Gab Ho received the B.S. degrees in Medical Information Technology Engineering from Soonchunhyang University in 2015. Now he is pursuing his Master degree in Medical Information Technology at Soonchunhyang University. His current research interests include biomedical signal processing, healthcare sensor application, and pattern recognition.

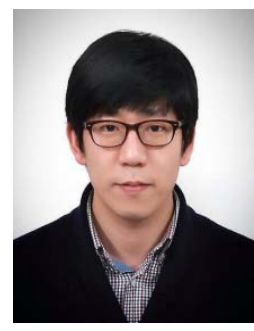

Se Dong Min received the M.S. and Ph.D. degrees in electrical and electronic engineering from the Department of Electrical and Electronics Engineering, Yonsei University, Seoul, in 2004 and 2010, respectively. He is currently an Assistant Professor at the Department of Medical IT Engineering, Soonchunhyang University, Asan, Korea. His research area includes biomedical signal processing, healthcare sensor application, and mobile healthcare technologies. 